\title{
Climate-economy feedbacks, temperature variability, and the social cost of carbon
}

Jarmo Kikstra1,2, Paul Waidelich ${ }^{3,4}$, James Rising ${ }^{3}$, Dmitry Yumashev ${ }^{5,6}$, Chris $\mathrm{Hope}^{7}$, and Chris Brierley²

1ENE Program, International Institute for Applied Systems Analysis (IIASA), Laxenburg, Austria (kikstra@iiasa.ac.at) ${ }^{2}$ Department of Geography, University College London, London, UK

${ }^{3}$ Grantham Research Institute on Climate Change and the Environment, London School of Economics, London, UK 4NERA Economic Consulting, Berlin, Germany *

${ }^{5}$ Pentland Centre for Sustainability in Business, Lancaster University, Lancaster, UK

${ }^{6}$ Institute of Sustainable Resources, University College London, London, UK

7Judge Business School, University of Cambridge, Cambridge, UK

${ }^{*}$ The views expressed in this presentation do not necessarily reflect the views of NERA Economic Consulting. 


\section{Study setup}
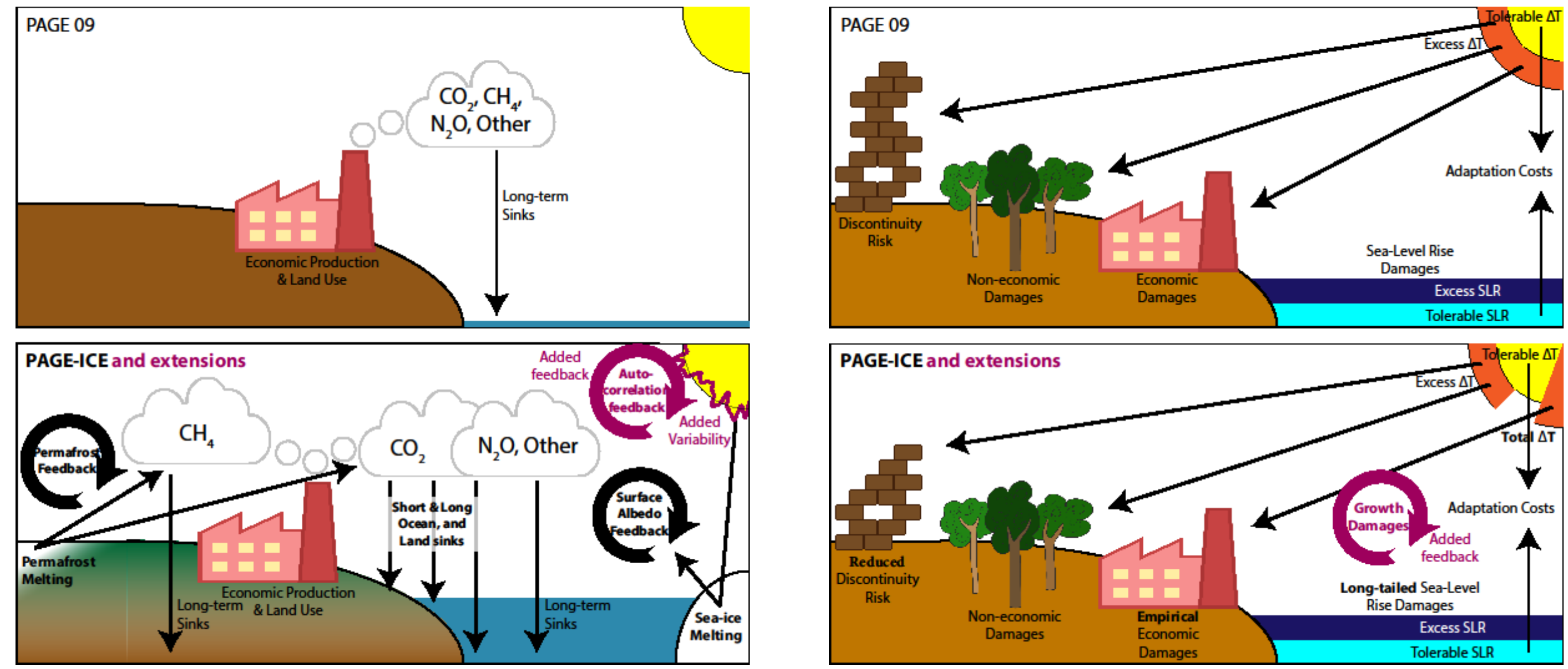


\section{Alterations in PAGE-ICE}
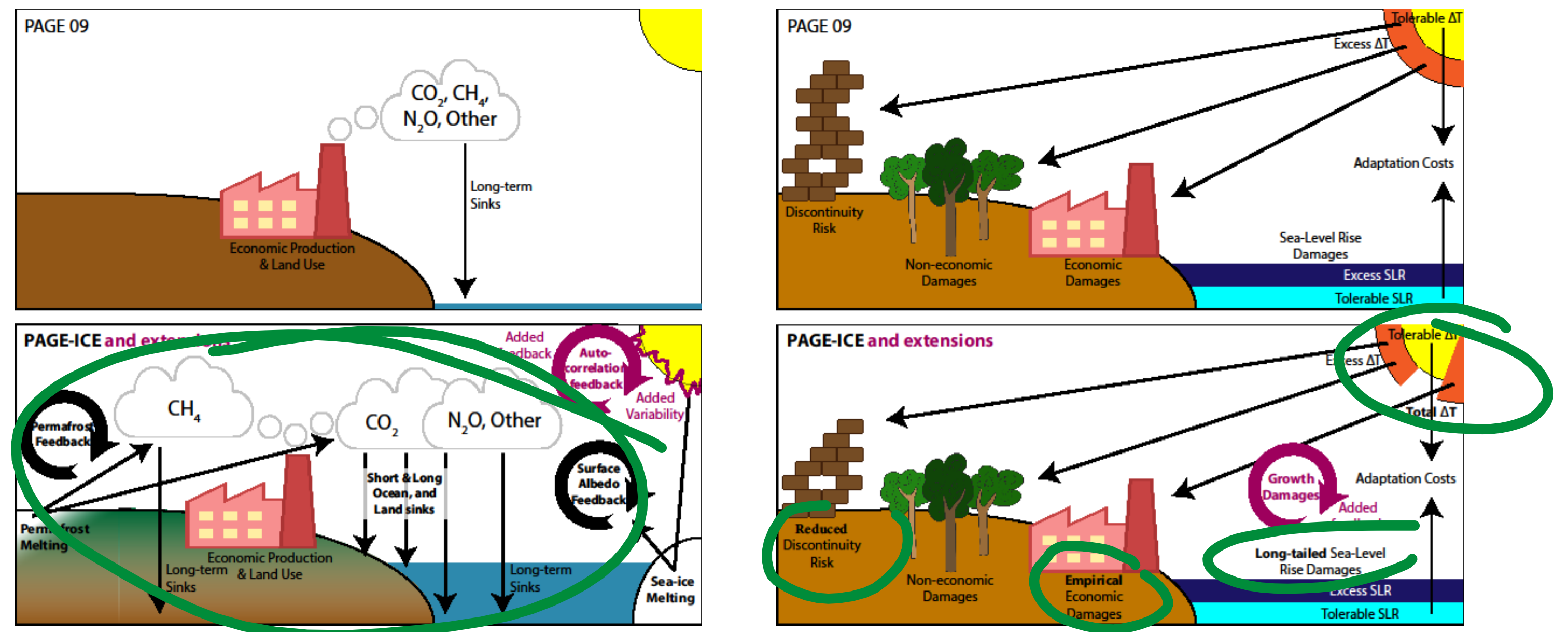

Hope, C. (2013). Critical issues for the calculation of the social cost of CO2: why the estimates from PAGE09 are higher than those from PAGE2002. Climatic Change, 117(3), 531-543. hittps:///doi. org/10.1007/s 10584-012-0633--2
Yumashev, D., Hope, C., Schaefer, K., Riemann-Campe, K., glesias-Suarez, F., Jafarov, E., .. Whiteman, G. (2019). 


\section{Updating the social cost of carbon for amongst others AR5, SAF, PCF, and empirical damages (SSP2-4.5)}

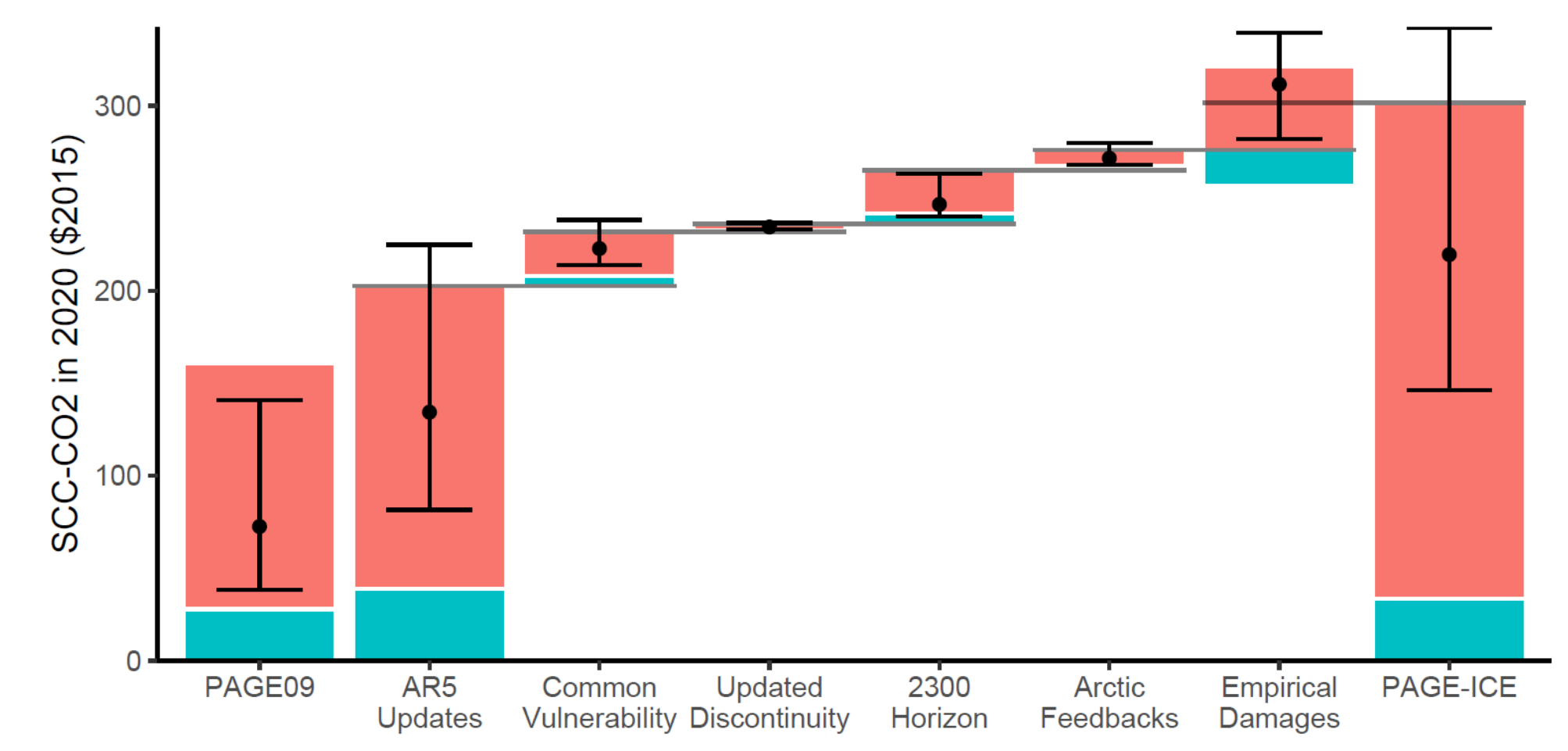

- Arctic feedbacks are not a large contributor to the SCC compared to other socioeconomic updates

Global South

Global North

- Increases in damages in the Global South make up for almost the entire increase in the SCC 


\section{Study setup}
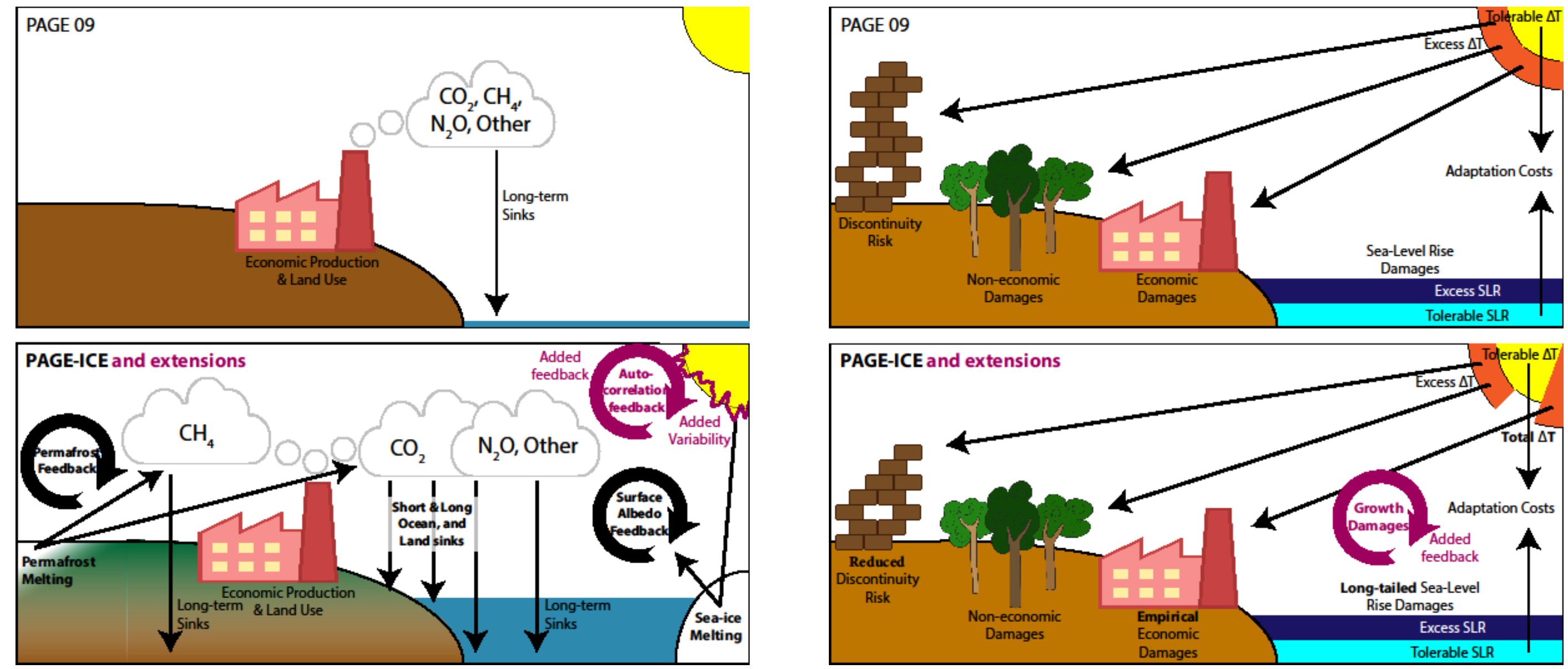


\section{Introducing the possibility of persistent damages}
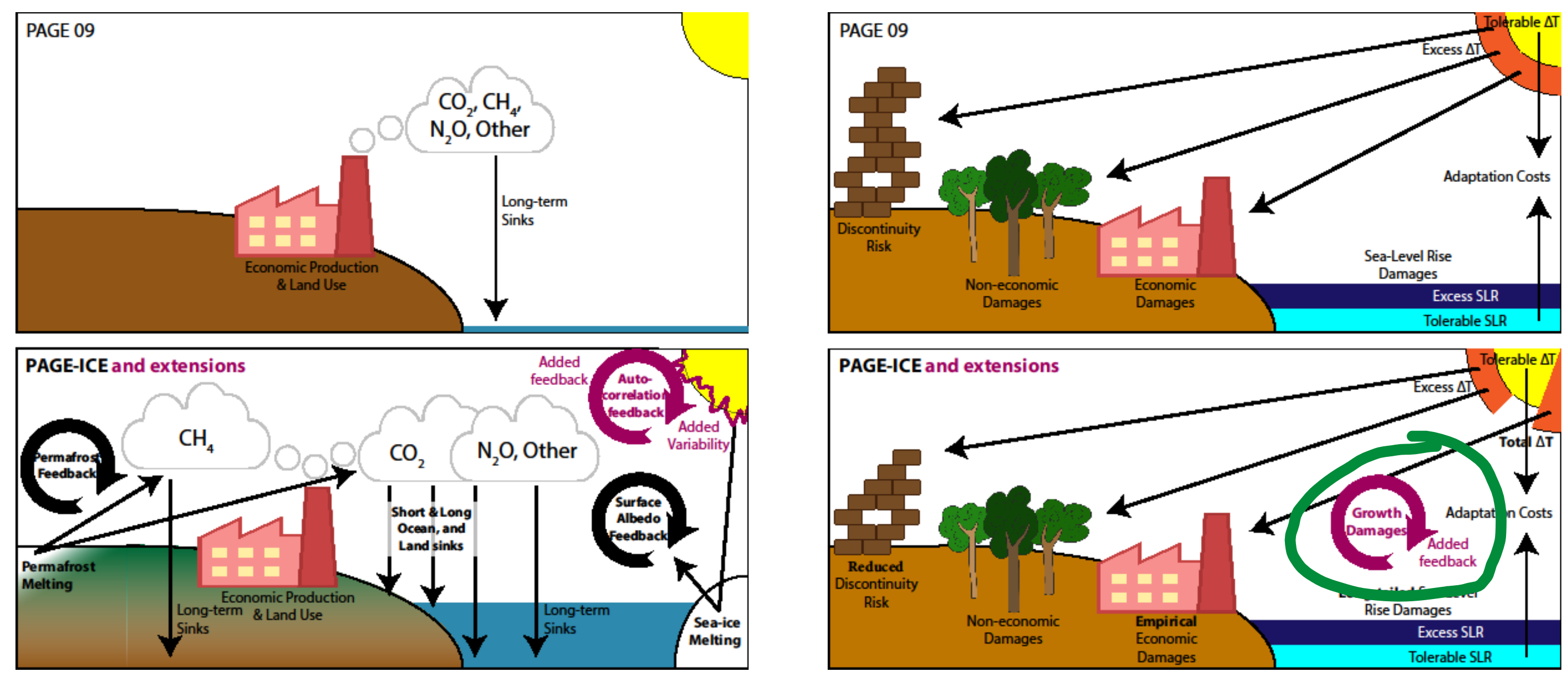


\section{Growth effects (SSP2-4.5) - adjusted GDP pathways}
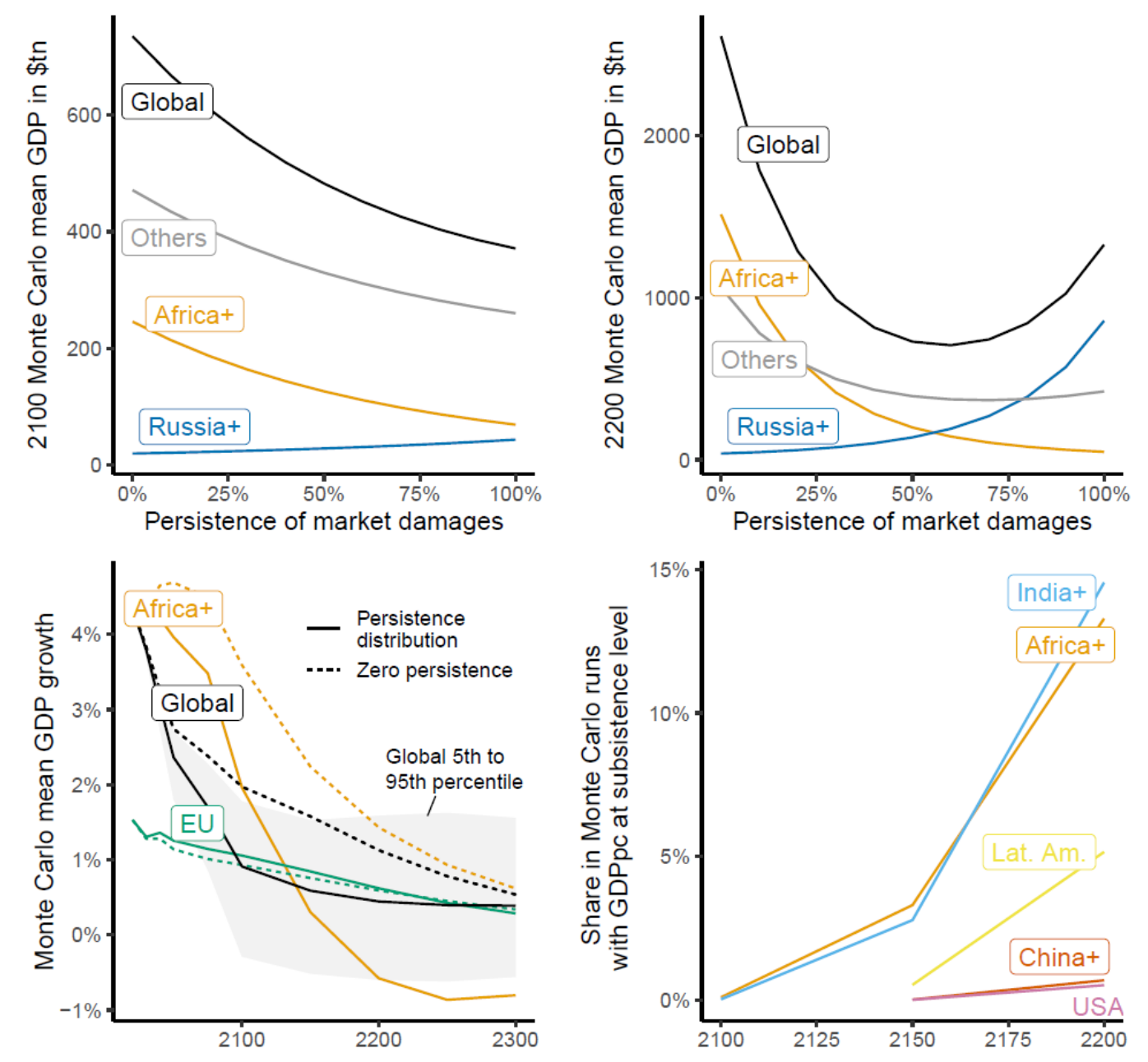

- GDP pathways are strongly moderated with increased levels of damage persistence

- Growth effects are regionally heterogeneous

- From 2100 on, a share of the model runs sees global GDP contraction
- In 2150, South Asia, Africa and the Middle East, and Latin America hit mean GDP/cap levels that are equal to absolute poverty levels for a considerable share of model runs. 


\section{Growth effects (SSP2-4.5) - effect on the SCC}

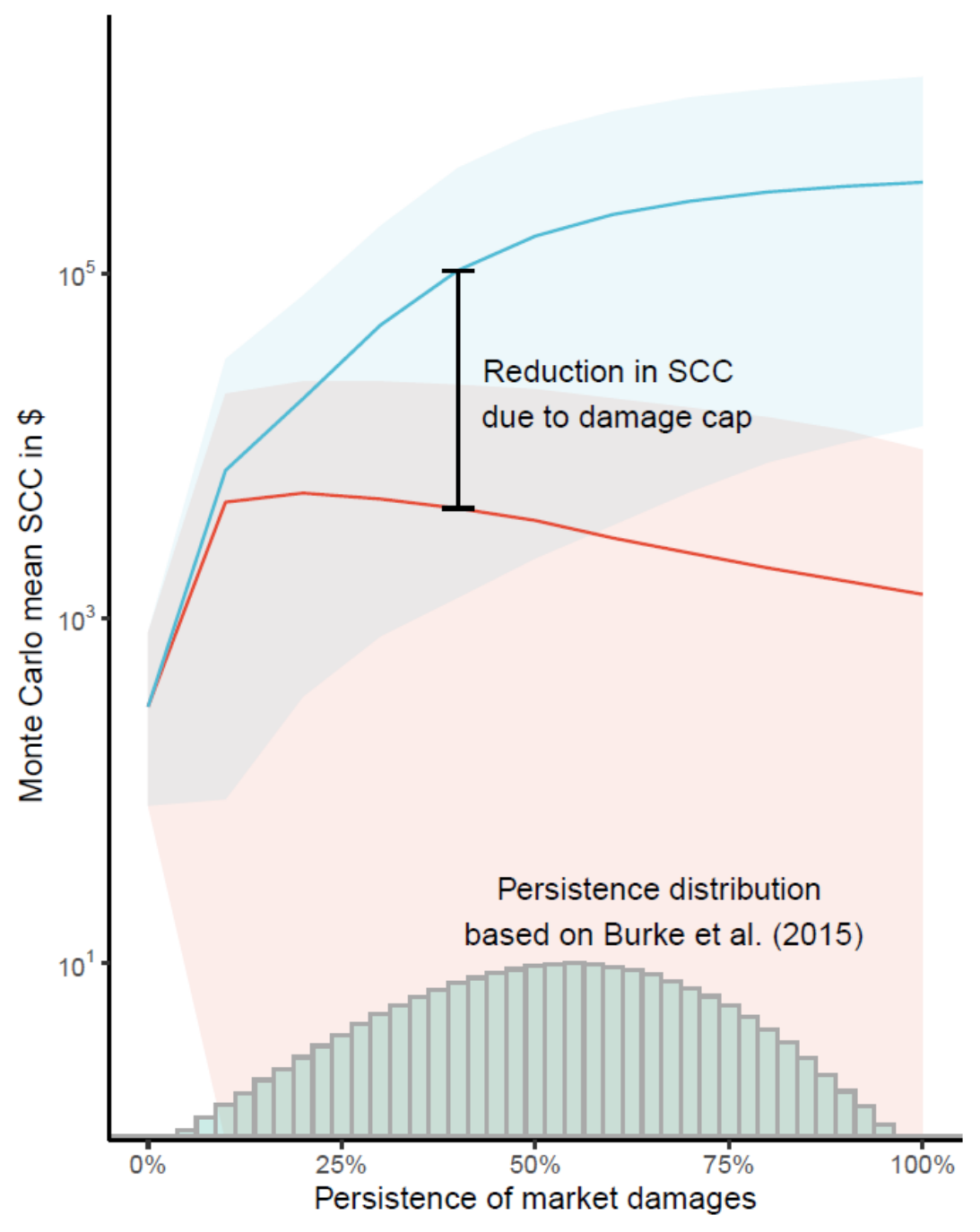

- With one lag, the implied damage persistence equals $52.8 \%$ of the immediate impact.

- Even if a minor share (10\%) of damages persist in the next year, the SCC increases $15 x$.

- For higher levels of persistence, an increasing share of model runs produce an SCC of zero as damages before the $\mathrm{CO} 2$ pulse already reach PAGE-ICE's cap on total damages ("statistical value of civilization")

- Growth effects, or damage persistence, deserves as much discussion in the SCC debate as discounting and climate sensitivity 


\section{Study setup}
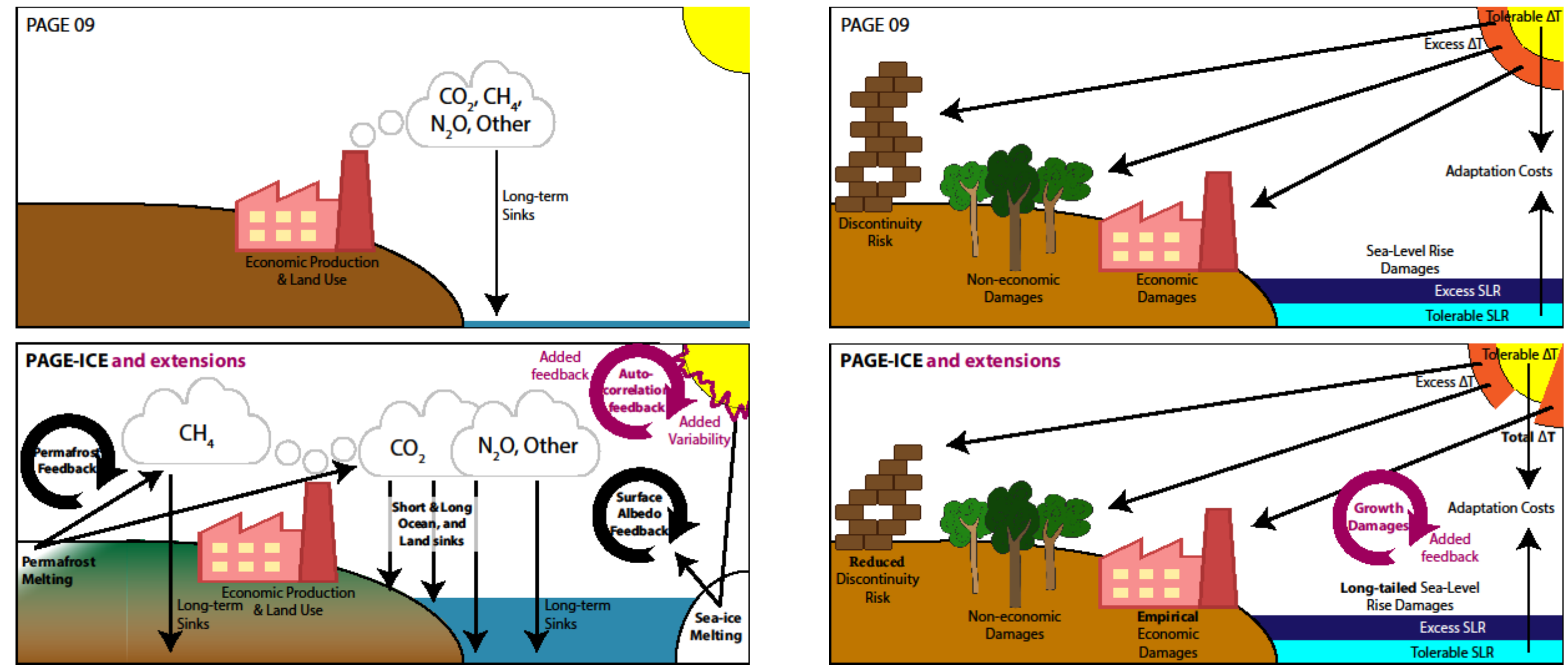


\section{Introducing climate variability}

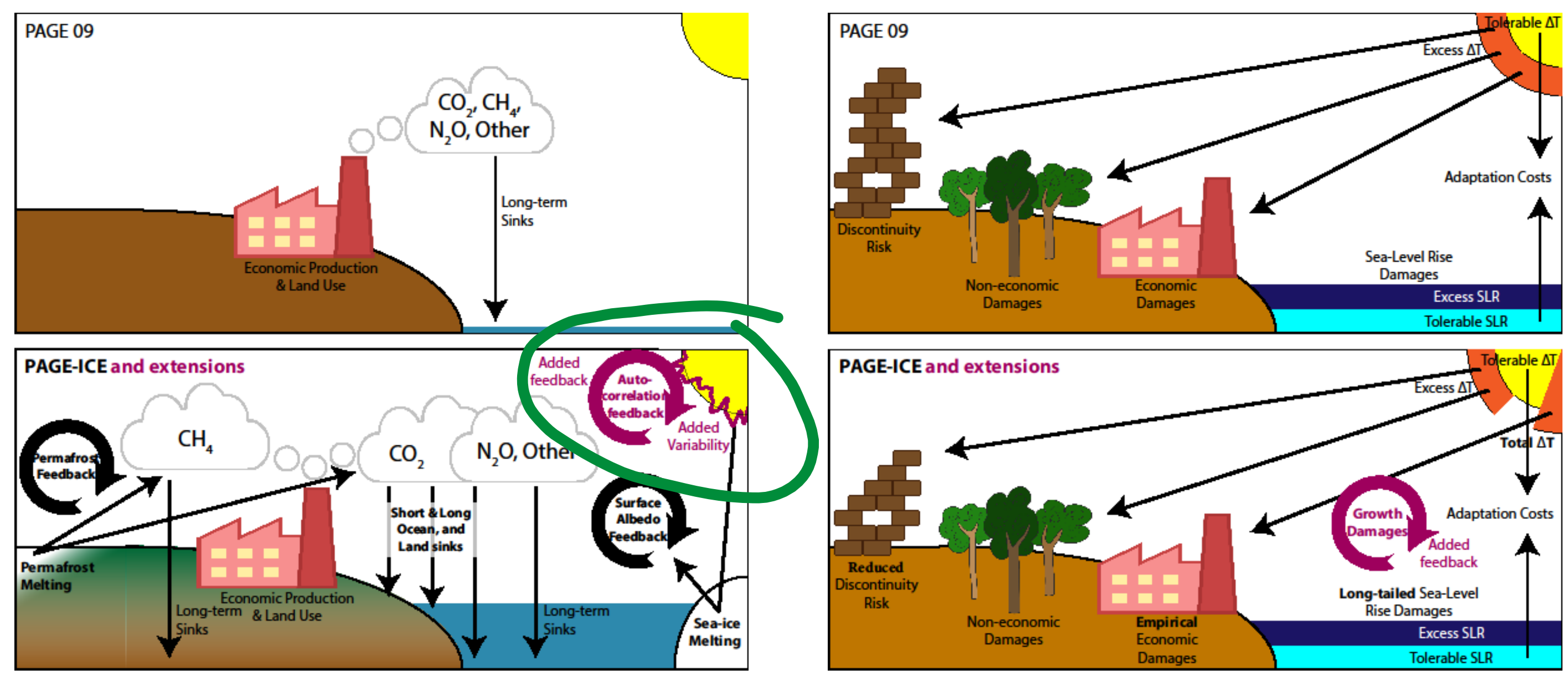




\section{Temperature anomalies (SSP2-4.5)}
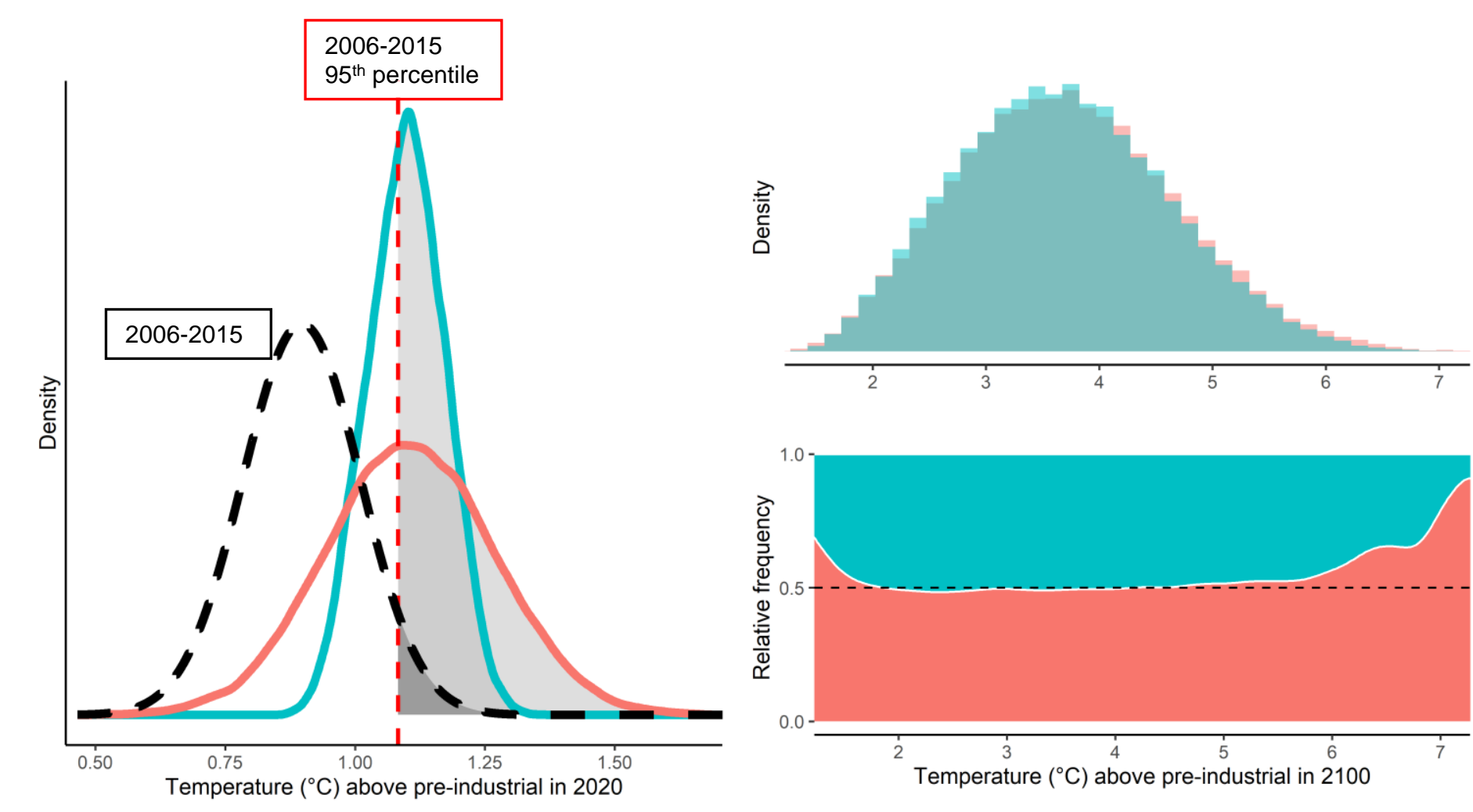

- Including temperature anomalies leads to a more realistic representation of possible temperature realisations

- This includes higher relative

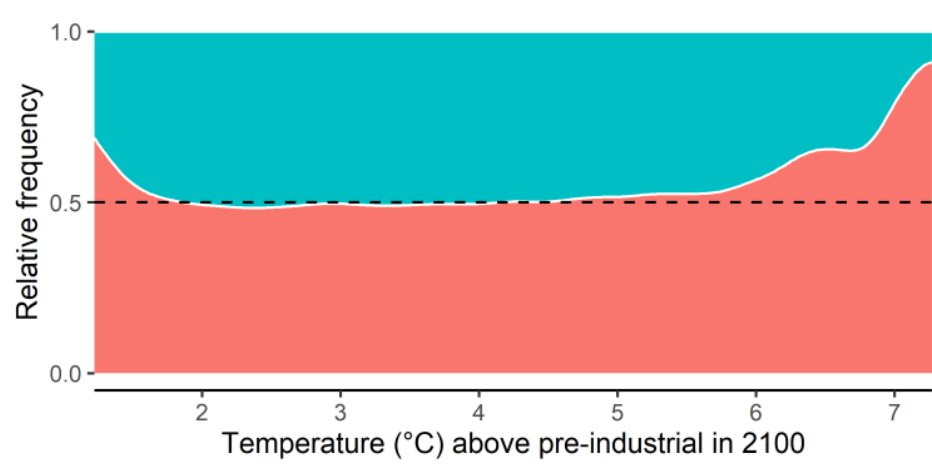
frequency of extreme mean annual temperatures throughout the modelling period.

Model variant

PAGE (annual)

PAGE (annual) with variability 


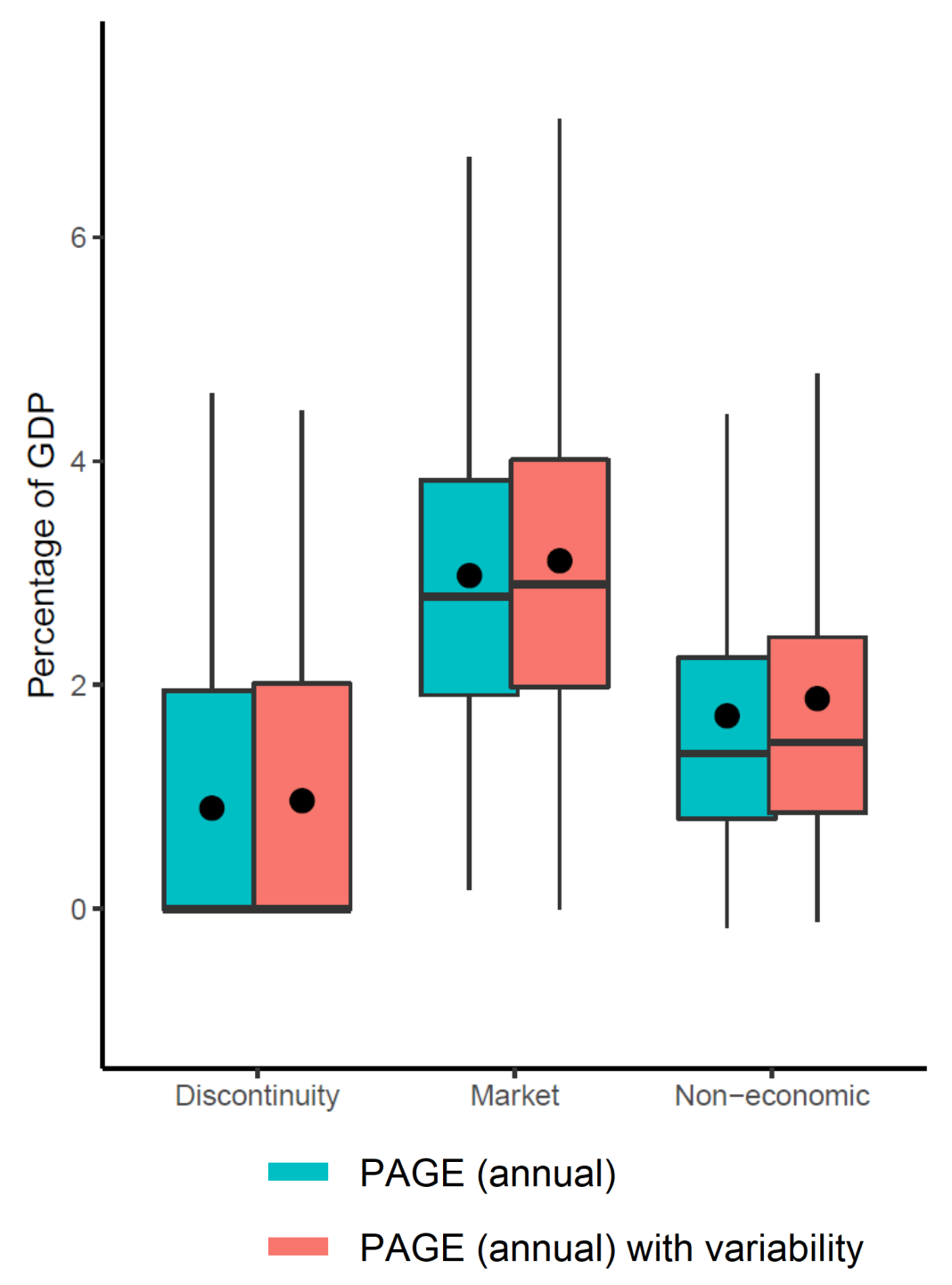

- Previous estimates underestimated climate impacts by not including temperature variability

- Temperature anomalies interact with other uncertain parameters and change the resulting SCC distribution significantly

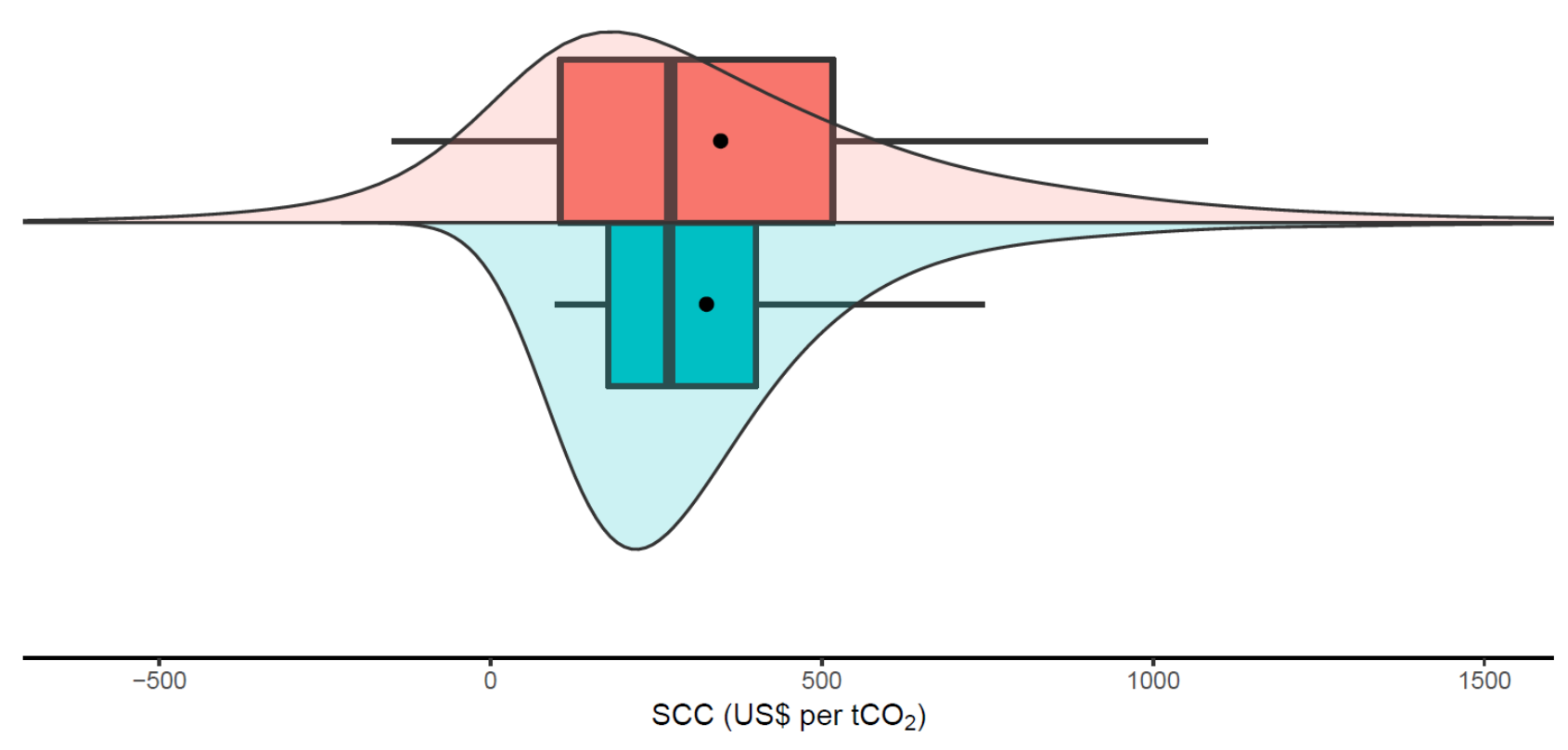




\section{Thank you for your time.}

\section{Any questions?}


Overview of SCC values under different climate and socioeconomic pathways
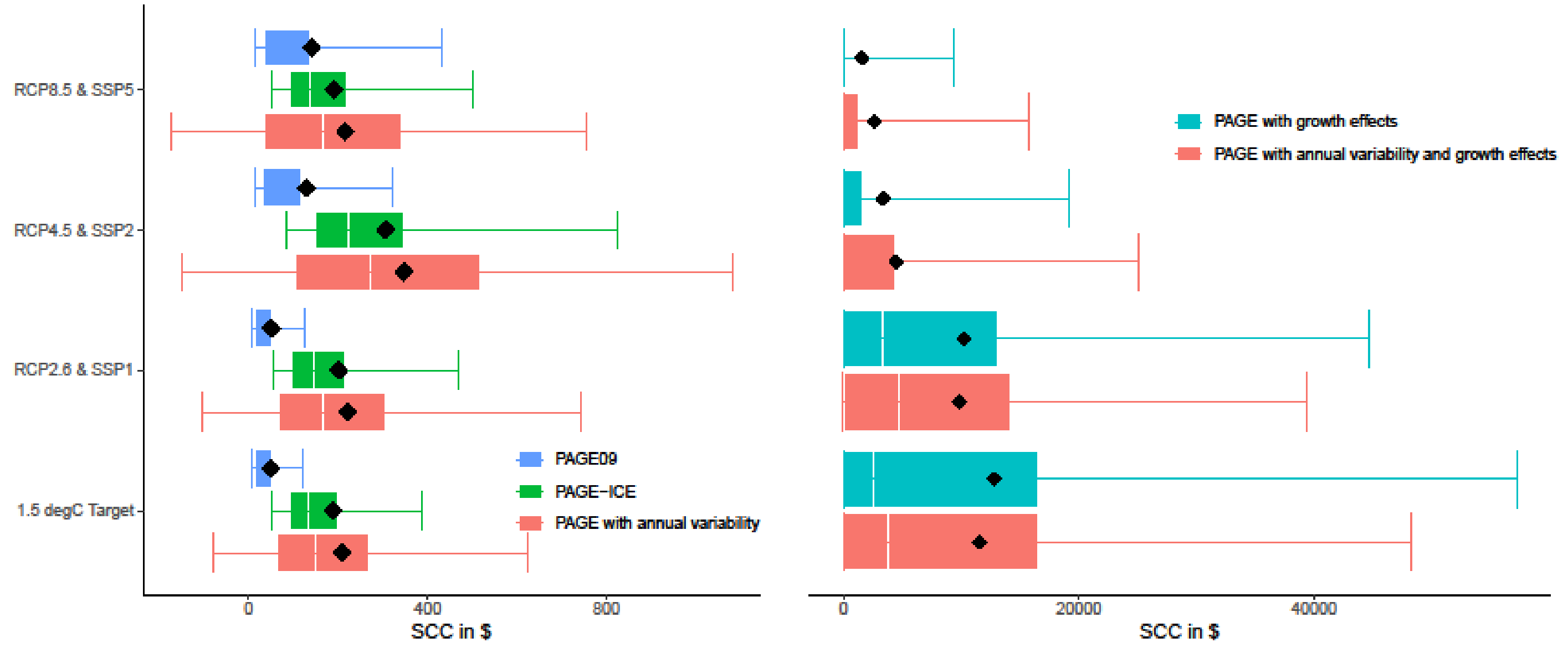


\section{GDP projections under growth effects (50,000 runs)}

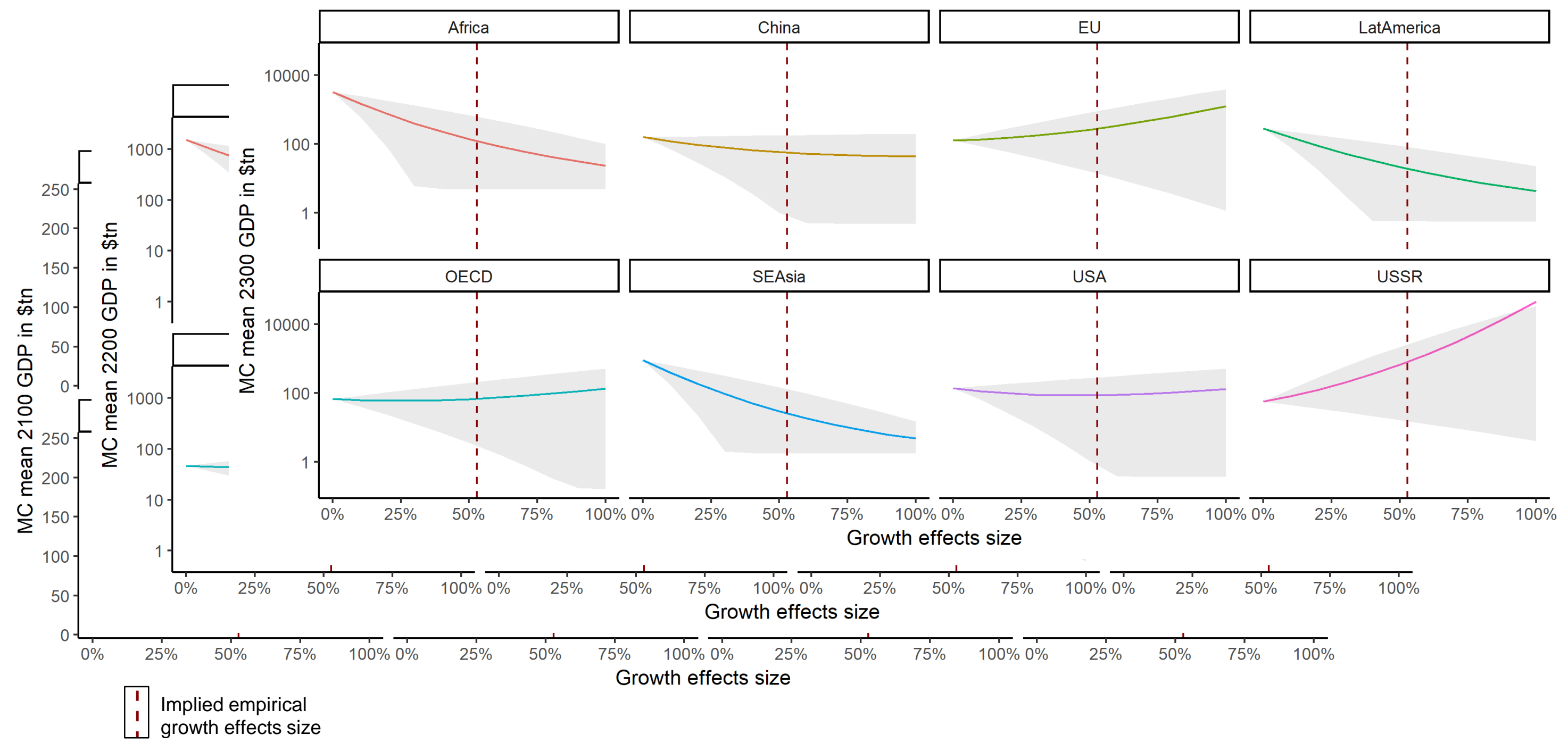

